\title{
Perceived stress and insomnia under the period of COVID-19: The mediating role of sense of security and the moderating role of family cohesion
}

\author{
Short Title: Stress and Insomnia Amidst COVID-19 \\ Baojuan $\mathrm{Ye}^{1}$, Jing $\mathrm{Hu}^{1}$, Hohjin $\mathrm{Im}^{2}$, Mingfan Liu ${ }^{1}$, Xinqiang Wang ${ }^{1}$ \& Qiang Yang ${ }^{1}$ \\ ${ }^{1}$ Jiangxi Normal University, ${ }^{2}$ University of California, Irvine
}

Baojuan Ye, Center of Mental Health Education and Research, School of Psychology, Jiangxi Normal University, 99 Ziyang Avenue, Nanchang 330022, China, Phone (86-079188120173), email (yebaojuan0806@163.com). Her major research focus on college students' development.

Jing Hu, Center of Mental Health Education and Research, School of Psychology, Jiangxi Normal University, 99 Ziyang Avenue, Nanchang 330022, China, Phone (86-079188120173), email (hj01021@163.com). Her major research focus on college students' development.

Hohjin Im, Department of Psychological Science, Universi of California, Irvine, email (hohjini@uci.edu). He is a social psychology doctoral student. His research focuses on ingroup favoritism. He incorporates perspectives of cultural psychology into his work, examining how those of different cultural backgrounds perceive and rationalize behavior in ethics.

Mingfan Liu, Center of Mental Health Education and Research, School of Psychology, Jiangxi Normal University, 99 Ziyang Avenue, Nanchang 330022, China, Phone (86-791-88123522), email(lmfxub@sina.com). Her major research interests include adolescent problem behaviors, and adolescents' social-emotional development.

Xinqiang Wang, Center of Mental Health Education and Research, School of Psychology, Jiangxi Normal University, 99 Ziyang Avenue, Nanchang 330022, China, Phone (86-79188120173), email (xinqiangw101@163.com). His major research interests include adolescent problem behaviors, and adolescents' meaning in life.

Qiang Yang, School of Education, Jiangxi Normal University, 99 Ziyang Avenue, Nanchang 330022, China, Phone (86-791-88120280), email (davidyang12345@163.com). His major research interest is adolescents' development.

Note: This is an unpublished preprint that has not yet undergone peer-review. This preprint is a working paper and thus is subject to changes with ongoing analyses, updates, and reconceptualization of related variables. This preprint is shared to facilitate quick dissemination of results. Reported findings and interpretations are not final and should not be used to guide policy or practices. 
Perceived stress and insomnia under the period of COVID-19: The mediating role of sense of security and the moderating role of family cohesion

\begin{abstract}
Although perceived stress has been shown to play an important role in insomnia, little is known about the mediating and moderating mechanisms underlying this relation. In particular, the outbreak of COVID-19 has undoubtedly had a significant impact on the physical and mental health of college students. The present study focused on Chinese college students during the COVID-19 pandemic and examined the mediating role of sense of security between perceived stress and insomnia and the moderating role of family cohesion. Chinese college students $(N=$ 1,187) completed the measures of perceived stress, sense of security, insomnia, and family cohesion. The results indicated that perceived stress was significantly and positively associated with insomnia, and sense of security partially mediated this relation. Moderated mediation analysis further indicated that family cohesion moderated the relation between perceived stress and sense of security. This relation became weaker for college students with higher levels of family cohesion. Results highlight the significance of identifying the mechanisms that moderate the mediate paths between perceived stress and college students' insomnia.
\end{abstract}

Keywords: COVID-19; Perceived stress; Insomnia; Family cohesion; Sense of security 


\section{Introduction}

COVID-19 has no doubt taken 2020 by a storm. The novel coronavirus continues to pose a global threat and has been described internationally as a public health emergency (World Health Organization, 2020). The emergence of COVID-19 has not only resulted in extensive human and economic loss, but has psychologically scarred those who were affected, whether directly or indirectly (Van Bavel et al., 2020). In particular, college students may be especially vulnerable to the negative peripheral outcomes of the pandemic. In China, the outbreak of COVID-19 occurred during their Winter recess of the academic year (i.e., equivalent of Summer Break in the United States). In an effort to curtail the spread of COVID-19 on university campuses, the Ministry of Education delayed the start of Spring Semester from February, 2020 to April, 2020 at the latest. For college students, attending university represents a special period of physical and psychological development - a critical stage in which one gains independent to formulate their own outlook on life, their environment, and world and to develop important social bonds. The sudden outbreak of COVID-19 and corresponding extension of an academic recess present obstacles in students' abilities to experience the social and learning experience of university life, which may have exacerbated their stress. Further, the extensive steps taken by the Chinese government in response to COVID-19 served as cues of the real and impending threats around them.

For many college students in 2020, the last familiar outbreak (e.g., SARS) likely occurred too early in their development to be remembered. For these students, the COVID-19 pandemic represents a novel threat to their and loved ones' well-being. Indeed, the explosive circulation of 
COVID-19-related information throughout media and fear amongst the general public may create an artificial echo chamber that further perpetuate a sense of panic, anxiety, depression, and insomnia among the populace. In an early examination of anxiety, depressive symptoms, and sleep problems among Chinese residents amidst the COVID-19 outbreak, younger individuals reported greater anxiety and depressive symptoms than their older counterparts (Huang \& Zhao, 2020). Despite the heightened risk factors among the younger populace, literature on insomnia related to COVID-19 has been scant. As the pandemic roars on, insomnia may become more common among those who experience pervasive stress from the virus outbreak. Indeed, as a key antecedent of physical and mental health (Vazsonyi et al., 2018; Williams et al., 2013), insomnia among youth is crucial to examine during the lifespan of the pandemic.

\subsection{Perceived stress and insomnia}

Insomnia refers to the subjective experience of a patient's dissatisfaction with their sleep duration and/or quality which subsequently affects their daily social functioning (Li et al., 2006). Stress has been evidenced to be a key factor in sleep, ultimately playing an important role in the onset and development of sleep disorders (Dou, Ming \& Gao, 2019; Redeker et al., 2020; Yan et al., 2010). However, the extent to which stress influences an individual is subjective and varies greatly. Indeed, the importance lies in the degree of perceived stress by the individual, rather than the objective stressors themselves (e.g., Falkman \& Lazarus, 1986). Perceived stress is an individual's subjective interpretation of internal and external events that place pressure on one's psyche, which not only impact one's cognitive functioning but also their emotions and physiological state (Lazarus \& Folkman, 1984). Pressure is most often a passive state when one's 
own capabilities and resources fail to meet the demands of the environment (Lazarus \& Folkman, 1984). According to Sterling and Eyer's (1988) concept of unsteady state of pressure response, excessive and prolonged stress will cause individuals' physical functioning to gradually become disordered and exhausted in addition to inducing an unstable mental and physical state, resulting in excessive endocrine system activity, excessive emotional awakening, and sleep disturbance (Sterling \& Eyer, 1988; Yan et al., 2010).

At present, several empirical studies have documented the negative relation between perceived stress and sleep quality (Eskildsen et al., 2017; Liu \& Liu, 2015; Zhang et al., 2014), such that higher perceived stress was related to greater likelihood of manifesting sleep problems (Gerber et al., 2010). In a large study of adolescents, Brand et al. (2011) found results that echoed this relation but also documented that insomnia worsened with increases in perceived stress. Despite the rich body of literature on the effects of stress on insomnia and sleep problems, the ongoing COVID-19 pandemic presents an unusual position with which youth find themselves situated in. With the widespread challenges brought about by the exposure of COVID-19, the youth are faced with unique set of stressors and little certainty or positivity in their immediate forecast.

Many businesses and agencies have shifted their approach in hiring, opting to be conservative and planning to hold out until the tail-end of the pandemic before embarking on risky talent acquisition decisions. The Chinese labor market has been no different; according to the Ministry of Education of China (2020), the number of college graduates in 2020 is expected to reach 8.74 million, further increasing the pressure of finding employment in an already 
saturated labor market. Further, college students' concerns and worries about their ability to graduate without complications and finding a satisfactory job post-graduation have become all too ubiquitous amidst the outbreak of the COVID-19. The backlog of these series of psychological burdens may eventually lead to a decline in sleep quality (Huan, 2018; Li et al., 2019). However, with the lack of information in the academic literature about the sleep consequences of general heightened stressors among youth, empirical evidence is required to test these propositions.

\subsection{Sense of security as a mediator}

The relation between stress and insomnia is unlikely to be a simple one. Kong (2010) reported that stress is an important factor influencing college students' sense of security. However, whether that sense of security serves as a psychological mechanism mediating stress and insomnia warrants further empirical exploration. Maslow's hierarchy of needs theory holds that sense of security, the subjective cognition and reaction to one's own security state separated from anxiety and fear, is a low-level need (Maslow et al., 1945; Cong \& An, 2004). An individual who loses their basic experience of security may experience a subsequent reduction in their life satisfaction and quality of life, likely exacerbating their negative emotional problems (Tang et al., 2018). The global spread of COVID-19 has established what may be construed as an optimal breeding ground for promoting psychological insecurity. Indeed, prior evidence of crisisrelated negative life events (e.g., emergencies, earthquakes, infectious diseases) have foreshadowed an increase in negative emotions (e.g., anxiety, panic) that ultimately deteriorated one's sense of security (Buwitzolim et al., 2018; Tong, 2004). Amidst the COVID-19 epidemic, 
college students may be faced with persistent worry for themselves and those around them. While the various measures and steps taken at the institutional level in response to the pandemic may be well-intended and epidemiologically warranted, these actions may also cue to students a sense of real impending threat of the virus. For instance, the sudden and forced closure of college campuses and non-essential businesses, transition to remote work, and bleak forecast of the labor market may all serve to cue to students a loss in their agentic control over their environment.

Accordingly, the loss of psychological security may deteriorate sleep quality among those affected. The theory of sleep disturbance process posits that excessive emotional arousal will interfere with the normal sleep process and subsequently affect sleep quality (Jin, Lan, \& Sun, 2011). In other words, the heightened sense of insecurity may leave one susceptible to the detriments of self- or environmentally-induced negative thoughts and emotions, producing a vicious circle of despondency that increases the risk of developing symptoms of insomnia (Roth, Lev-Wiesel, \& Shochat, 2019). Given that COVID-19 may induce a qualitatively different sense of insecurity from otherwise normative times, an empirical examination of the robustness of prior findings may prove fruitful. Thus, this study expands on prior research to examine the mediating role of psychological security in the relation between perceived stress and insomnia symptoms.

\subsection{Family cohesion as a moderator}

As COVID-19 has forced many residents to shelter at home in an effort to curb the spread of the virus, the close proximity to their families has likely been a constant factor for many college students. While there is little doubt that family plays a key factor for the healthy 
development of youth, the role of family cohesion within the COVID-19 social ecology remains unclear. Based on Bronfenbrenner's ecological systems theory (Bronfenbrenner, 2005), family factors are important social support systems that promote both individual physical and mental health and also serve to improve life satisfaction. Family cohesion is defined as the emotional bonding and interdependence of family members - the degree to which individuals are accepted in the family system (Olson, 1986). Prior studies have shown that family cohesion has a positive effect on one's sense of security (e.g., Davies et al., 2006; Cummings et al., 2010) and serves as a protective factor for individuals' emotional adaptation (Bannink et al., 2013; Letourneau et al., 2011). In other words, the stronger the family cohesion that one perceives, the higher their sense of security (Kliewer et al., 2006; Qin et al., 2015).

Indeed, individual characteristics may interact with environmental factors to influence one's trajectory of development (Magnusson \& Stattin, 1998). As discussed before, perceived stress may be deemed a risk factor (Dean \& Lawrence, 1983; Gomes, Faria, \& Lopes, 2016) for developing a sense of insecurity (Kong, 2010) while ecological resource factors may buffer or weaken the adverse impact of risk factors ( $\mathrm{Li}, 2012)$. Thus, it may be inferred that family cohesion, as a protective factor (Coe et al., 2017; Jobe-Shields et al., 2017), may buffer against the risk of perceive stress and also increase sense of security. Specifically, college students who believe their family cohesion to be strong may be report a weaker relation between perceived stress and sense of security, and vice versa. That is, high mutual support and low conflict among family members may reduce the risk of consequences of perceive stress, increase one's sense of security, and subsequently be less likely to develop insomnia. 


\subsection{The present study}

Figure 1. The proposed moderated mediation model.

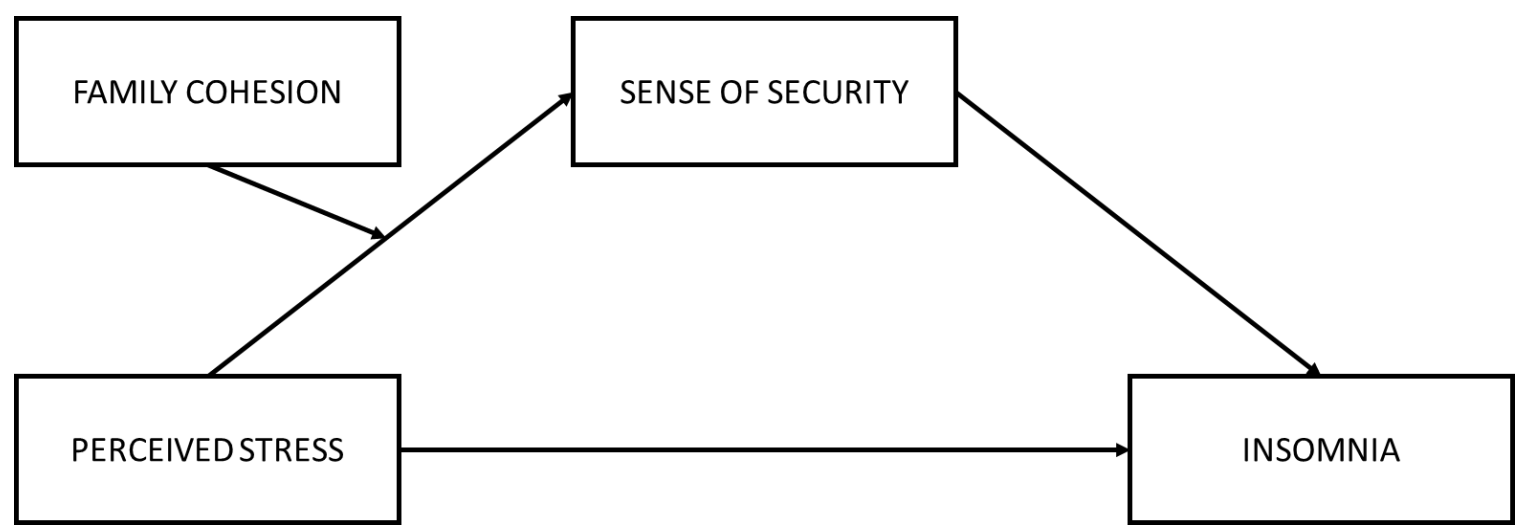

Taken together, the aims of the current study were twofold. First, the current study tested whether sense of security would mediate the relationship between perceived stress and insomnia. Second, we tested whether family cohesion would moderate the association between perceived stress and sense of security (Figure 1). Based on the literature review, we proposed the following hypotheses:

Hypothesis 1: Sense of security would mediate the relationship between perceived stress and insomnia.

Hypothesis 2: Family cohesion would moderate the association between perceived stress and sense of security.

\section{Method}

\subsection{Participants}

The present study conveniently sampled a total of 1,359 college students across China. After excluding participants with invalid data (i.e., missing values), 1,187 participants were 
included in the final analyses. Among them, $43.81 \%$ of these participants were first year standing, $21.23 \%$ were second year standing, $26.53 \%$ were third year standing, and $8.42 \%$ were fourth year standing or higher. The mean age of the participants was $20.09(S D=1.42$, range $=$ 17-24).

\subsection{Measures}

\subsubsection{Perceived Stress scale}

Perceived stress was measured with the Perceived Stress Scale (Cohen, Kamarch, \& Mermelstein, 1983); Chinese version revised by Yang and Huang (2003). This scale consisted of 14 items (e.g., "Getting upset when something unexpected happens") and included two dimensions: 1$)$ nervous feeling ( 7 items) and 2) out of control (7 items). Each item was rated on a 5 -point scale $(1=$ never to $5=$ always $)$, with higher total scores indicating higher levels of perceived stress. The Chinese version of Perceived Stress Scale has been demonstrated to be reliable (Liu, 2016). In the present study, Cronbach's alpha for this scale was 0.82 .

\subsubsection{Sense of security scale}

Sense of security was measured by the Sense of Security Scale (Maslow et al., 1945); Chinese version revised by Cong and An (2004). This scale consisted of 16 items (e.g., 'I'm afraid to establish and maintain an intimate relationship with others") and included two dimensions: 1) interpersonal security ( 8 items) and 2) sense of certainty and control over future life (8 items). Each item was rated on a 5 -point scale $(1=$ absolutely the same to $5=$ very different), with higher total scores indicating higher levels of sense of security. The Chinese 
version of Sense of Security Scale has been demonstrated to be reliable (Zhang et al., 2018). In the present study, Cronbach's alpha for this scale was 0.94 .

\subsubsection{Family cohesion scale}

Family cohesion was measured by the Family Cohesion Scale (Olson et al., 1982);

Chinese version revised by Fei et al. (1991), which consisted of 16 items (e.g., "Family members are familiar with each other's close friends"). Each item was rated on a 5-point scale $(1=$ never to 5 always), with higher total scores indicating higher levels of family cohesion. The Chinese version of Family Cohesion Scale has been demonstrated to be reliable (Lin et al., 2018). In the present study, Cronbach's alpha for this scale was 0.90 .

\subsubsection{Insomnia scale}

Insomnia scale was compiled based on the Pittsburgh Sleep Quality Scale (Buysse et al., 1989). The scale included 14 items (e.g., "Over the past half month, how is your overall sleep quality"). This scale consists of three dimensions: 1) including subjective sleep quality (three items), 2) sleep disorder (six items), and 3) daytime dysfunction (four items). Each item was rated on a 4-point scale assessing one's dissatisfaction $(1=$ Very Satisfied to $4=$ Very Dissatisfied), frequency ( $1=$ Always to $4=3-5$ times a week), duration $(1=$ More than 8 hours to $4=$ Less than 5 hours $)$, and reoccurrence $(1=$ Not at all to $4=$ Almost every day $)$, with higher total scores indicating higher levels of insomnia. In the present study, Cronbach's alpha for this scale was 0.85 .

\subsection{Procedures}


This investigation was approved by the first author's university Ethics Committee. All study participants over the age of majority provided informed consent. For participants under the age of majority, consent of their legal guardian was obtained. All participants were informed of the importance of the authenticity and completeness of their answers and were reassured that their responses would not be linked to their identities. The anonymity of the study was emphasized before data collection. Participants were then directed to an anonymous survey in which they completed the measures listed above.

\subsection{Data analysis}

First, data screening revealed that there were no outliers in the data. Responses with missing data were excluded from the data processing. Second, whether data followed normal distribution was examined. Square root transformation on the overall mean scores were conducted to approximate normal distributions. The transformed variables were used for the following analyses.

The moderated mediation model analysis was used according to the following steps. First, descriptive statistics and Pearson correlations were calculated among the study variables. Second, PROCESS macro for SPSS (Model 4) was applied to examine the mediating effect of sense of security (Hayes, 2013). Third, the PROCESS macro (Model 7) was applied to examine the moderating effect of family cohesion on the indirect links between perceived stress and insomnia. The models relied on 5,000 iterations of bootstrap confidence intervals (CIs) to estimate the effects in the Model 4 and Model 7 mediation analyses (Hayes, 2013). An effect is 
regarded as significant if the CIs do not include zero within its intervals. All study variables were standardized in Model 4 and Model 7 before data analyses.

\section{Result}

\subsection{Preliminary analyses}

Table 1. Descriptive statistics and correlations among variables of interest.

\begin{tabular}{lccccccc}
\hline \multicolumn{1}{c}{ Predictors } & M & SD & Skewness & Kurtosis & $\mathbf{1}$ & $\mathbf{2}$ & $\mathbf{3}$ \\
\hline 1. Perceived stress & 2.73 & 0.55 & -0.762 & 2.126 & - & & \\
2. Sense of security & 2.49 & 0.71 & -0.120 & -0.030 & $-0.257^{* *}$ & - & \\
3. Family cohesion & 3.13 & 0.61 & 0.164 & 1.699 & $-0.401^{* *}$ & $0.079^{* *}$ & - \\
4. Insomnia & 2.09 & 0.57 & 0.829 & 0.435 & $0.217^{* *}$ & $-0.449^{* *}$ & $-0.084^{* *}$ \\
\hline
\end{tabular}

Note: ${ }^{*} p<0.05,{ }^{* *} p<0.01,{ }^{* * *} p<0.001$

The means, standard deviations, skewness, kurtosis, and Pearson correlations for the study variables are reported in Table 1 . The skewness and kurtosis values showed that all variables were normally distributed (i.e., skewness $<|2.0|$ and kurtosis $<\mid 7.0$; Hancock \& Mueller, 2010). Perceived stress was negatively correlated with sense of security and positively correlated with family cohesion and insomnia. Sense of security was negatively correlated with insomnia and positively correlated with family cohesion, albeit weakly. Family cohesion was weakly negatively correlated with insomnia.

\subsection{Testing for mediation effect}

Table 2. Testing the mediation effect of Perceived Stress on Insomnia.

\begin{tabular}{|c|c|c|c|c|c|c|}
\hline \multirow[b]{2}{*}{ Predictors } & \multicolumn{2}{|c|}{$\begin{array}{c}\text { Model 1 } \\
\text { (Insomnia) } \\
\end{array}$} & \multicolumn{2}{|c|}{$\begin{array}{c}\text { Model } 2 \\
\text { (Sense of Security) }\end{array}$} & \multicolumn{2}{|c|}{$\begin{array}{c}\text { Model 3 } \\
\text { (Insomnia) } \\
\end{array}$} \\
\hline & $\beta$ & $t$ & $\beta$ & $t$ & $\beta$ & $t$ \\
\hline Perceived stress & 0.22 & $7.67 * * *$ & -0.26 & $-9.14 * * *$ & 0.11 & $4.10 * * *$ \\
\hline Sense of security & & & & & -0.42 & $-15.77 * * *$ \\
\hline
\end{tabular}


$R^{2}$

$F$

Note: ${ }^{*} p<0.05,{ }^{* *} p<0.01,{ }^{* * *} p<0.001$

In Hypothesis 1, we proposed that sense of security would mediate the relation between perceived stress and insomnia. This hypothesis was tested with Model 4 of the PROCESS macro (Hayes, 2013), which requires the three steps: (a) whether there is a significant association between perceived stress and insomnia (see Model 1 in Table 2); (b) whether there is a significant association between perceived stress and sense of security traits (see Model 2 in Table 2); and lastly, (c) whether there is a significant association between sense of security and insomnia while controlling for perceived stress (see Model 3 in Table 2). The results first revealed that perceived stress was positively related to insomnia $(\beta=0.22, t=7.67, p<0.001)$ (Model 1). Second, perceived stress was negatively associated with sense of security $(\beta=-0.26, t$ $=-9.14, p<0.001)($ Model 2). Third, sense of security was negatively related to insomnia controlling for perceived stress $(\beta=-0.42, t=-15.77, p<0.001)$. The positive direct association between perceived stress and insomnia remained significant, however, suggesting a partial mediation effect $(\beta=0.11, t=4.10, p<0.001$ ) (see Model 3 in table 2). Results from the simple mediation PROCESS macro indicated that sense of security partially mediated the relation between perceived stress and insomnia (indirect effect $=0.107, S E=0.016,95 \% C I=[0.077$, $0.139]$.

\subsection{Moderated mediation effect analysis}

Table 3. Testing the moderated mediation effects of Perceived Stress on Insomnia. 


\begin{tabular}{lcccccc}
\hline & \multicolumn{3}{c}{$\begin{array}{c}\text { Model 1 } \\
\text { (Sense of Security) }\end{array}$} & \multicolumn{3}{c}{$\begin{array}{c}\text { Model 2 } \\
\text { (Insomnia) }\end{array}$} \\
\cline { 2 - 7 } Predictors & $\boldsymbol{\beta}$ & $\boldsymbol{t}$ & $\mathbf{9 5 \%} \boldsymbol{C I}$ & $\boldsymbol{\beta}$ & $\boldsymbol{t}$ & $\mathbf{9 5 \%} \boldsymbol{C I}$ \\
\hline Perceived stress & -0.34 & $-11.44^{* * *}$ & $(-0.40,-0.28)$ & 0.11 & $4.10^{* * *}$ & $(0.06,0.16)$ \\
Family cohesion & 0.24 & $8.05^{* * *}$ & $(0.18,0.30)$ & & & \\
PS $\times$ FC & 0.08 & $4.90^{* * *}$ & $(0.05,0.12)$ & & & \\
Sense of security & & & & -0.42 & $-15.77^{* * *}$ & $(-0.47,-0.37)$ \\
$R^{2}$ & & 0.123 & & & 0.460 & \\
$F$ & & $55.31^{* * *}$ & & & $159.93^{* * *}$ & \\
\hline
\end{tabular}

Note: ${ }^{*} p<0.05,{ }^{* *} p<0.01,{ }^{* * *} p<0.001$

To test the moderated mediation model, we used Model 7 of the SPSS macro PROCESS compiled by Hayes (2013). The results of the family cohesion moderation test are shown in Table 3. As shown in Model 1 of Table 3, the product (i.e., interaction term) of perceived stress and family cohesion had a positive relation to sense of security $(\beta=0.08, t=4.90, p<0.001)$. For descriptive purposes, the predicted sense of security against perceived stress, separated by low and high levels of family cohesion, are provided in Figure 2. Simple slope tests showed that for college students with low family cohesion, perceived stress was negatively related to sense of security $(\beta=-0.42, p<0.001)$. For college students with high family cohesion, perceived stress remained a negative predictor of sense of security but was noticeably weaker $(\beta=-0.26, p<$ 0.001). However, the moderating effect of family cohesion was not significant in the relationship between perceived stress and insomnia. In sum, these results indicated that family cohesion moderated indirect associations between perceived stress and insomnia via sense of security, supporting Hypothesis 2.

Figure 2. Interaction between perceived stress and family cohesion on security. 


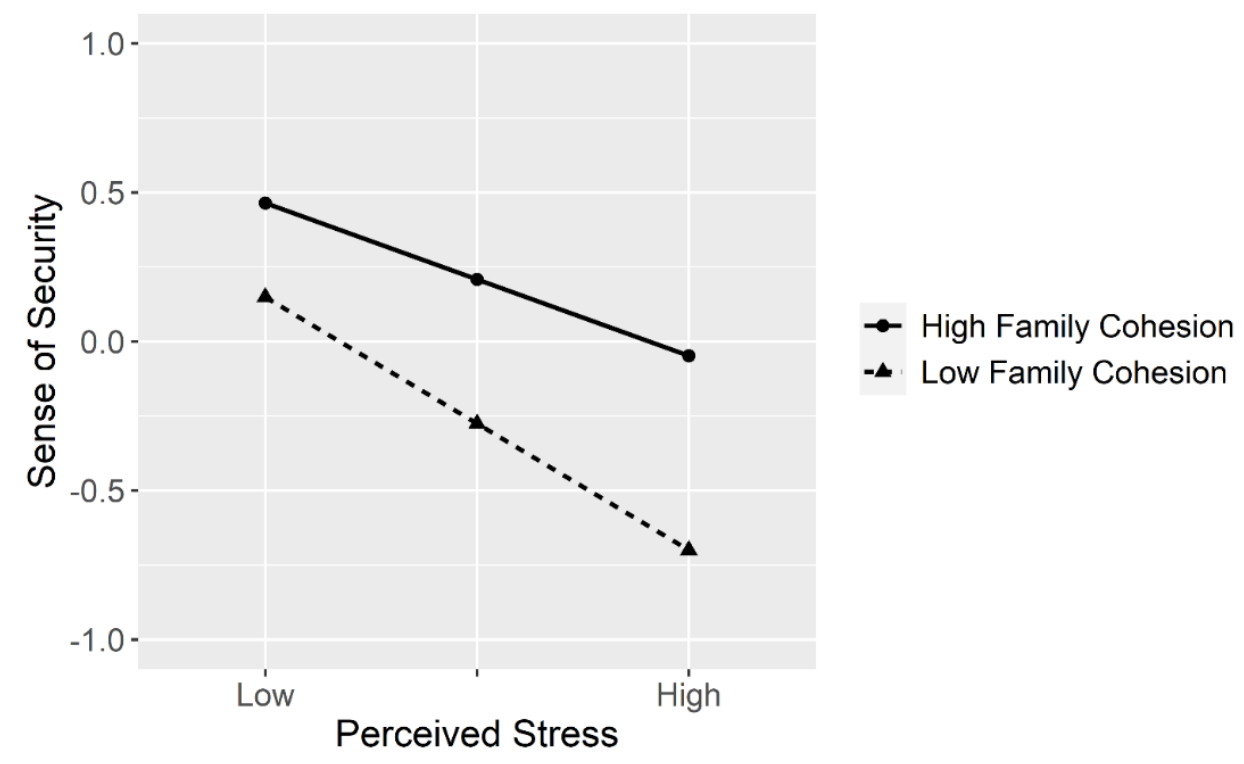

\section{Discussion}

Although the effect of perceived stress on insomnia has accumulated considerable empirical support over the years, there have been little inquiry into the relation between perceived stress and insomnia amidst the COVID-19 pandemic. Thus, the underlying mediating and moderating mechanisms have been less clear. In this study, a moderated mediation model was conducted to test how the relation between perceived stress and insomnia could be nuanced through inclusion of various mechanisms. Our findings indicated that perceived stress was significantly and positively associated with insomnia among Chinese college students, and sense of security partially mediated this relation. Furthermore, family cohesion moderated the relation between perceived stress and sense of security wherein this relation became weaker for college students with higher levels of family cohesion.

\subsection{The mediating role of sense of security}


The present study is the first to demonstrate the mediating role of sense of security in the association between perceived stress and insomnia. That is, perceived stress was negatively related to one's sense of security, which in turn, was positively related to the development of insomnia symptoms. Therefore, a lack of sense of security was not only an outcome of perceived stress, but also a catalyst for insomnia. Furthermore, it is worth noting that sense of security only partially mediated the relation between perceived stress and insomnia, suggesting that the remaining direct effect of perceived stress still remains a prominent factor in predicting college students' insomnia.

In addition to the overall mediation result, each of the separate links in our mediation model is noteworthy. For the first step of the mediation process (i.e., perceived stress $\rightarrow$ sense of security), the present study found that perceived stress was negatively related to one's sense of security. This negative relation may have stemmed from the fact that during the COVID-19 outbreak, college students may have become more acutely aware of their own health conditions. With heightened awareness and attention to one's physiological state, any cues of health anomalies may have induced greater sense of panic or suspicion (Ayittey et al., 2020).

Secondly, students may have also been worried about the potential impacts of the pandemic on their studies as, at least in China, the reopening of the academic school year was delayed. This is in contrast to other societies, like the United States, where many universities and school districts opted to transition to remote learning rather than enforcing a prolonged recess from academic instruction. For college students in their last or penultimate year, the sudden advent of COVID-19 may have placed extra challenges to the completion of their graduation 
theses or job search efforts, further exacerbating any underlying uneasiness or anxiety. These negative thoughts may have contributed to a decline in their sense of security. However, because perceived stress is a generic measurement of one's current stressful state, it does not nuance the specific stressors targeted towards COVID-19 outcomes. In other words, while we speculate that factors discussed prior (e.g., labor market) are likely antecedents of students' current perceived stress, further research may be needed to confirm such propositions. Specifically, qualitative research may especially be beneficial to identify the points of stressors deemed most critical for this age group as they transition from adolescence to young adulthood.

For the second path of the mediation model (i.e., sense of security $\rightarrow$ insomnia), the present study found that sense of security was negatively related to insomnia symptoms. The outbreak of COVID-19 and the series of rapid societal changes brought about by said pandemic likely challenged the foundation of students' sense of security. For students with a lower sense of security, negative emotions and thoughts may be pervasive obstacles in maintaining normative daily functioning.

With the outbreak of the COVID-19, college students have an insecure sense of their surroundings and uncontrollable future lives, which causes individuals to continue to think about these negative emotions, which makes the brain overactive and difficult to sleep (Li et al., 2019). And according to the cognitive model of insomnia (Harvey, 2002), negative emotions (such as insecurity etc.) can cause individuals to have cognitive deviations in the face of irritating factors related to sleep problems (such as stressful life events), this cognitive bias makes them excessively focused and negative assess the underlying factors that leads to a decline in the sleep 
quality. In addition, college students under perceived stress feel sense of insecurity, timidity, low emotional expression, low self-identity, and low self-esteem, which increase the risk of insomnia (Donarelli et al., 2019). Studies have shown that negative emotions can cause sleep disturbances such as short sleep latency, reduced deep sleep, high levels of awakening, early wake up, and difficulty falling asleep after waking up (McCann \& Stewin, 1998; Johnson et al., 2006).

\subsection{The moderating role of family cohesion}

Results also showed that family cohesion moderated the relation between perceived stress and sense of security. Specially, the relation between perceived stress and sense of security was greater for college students with low family cohesion than for those with high family cohesion, consistent with prior evidence (Hak \& Bongwhakim, 2018; Ye, Lie, \& Yang, 2019). Because college students may still be dependent on their family for financial and emotional support, those from incohesive families may be left to face obstacles, difficulties, and challenges alone. With the COVID-19 outbreak forcing many to shelter at home, a weak family dynamic may also fail in providing social support. Thus, it may be such that one's perceived stress will have free reign to exacerbate their inner fears and insecurities. This is in comparison to those who report a strong family cohesiveness. Indeed, as evidenced in this study and by prior studies, strong family cohesion led to a greater sense of security (Demby, Riggs, \& Kaminski, 2017) and can foster the development of good self-cognition, sense of control, and positive interpretations and expectations of others and events, all which can aid in the establishment of a strong sense of security (Mikulincer \& Shaver, 2015). Further, we may also rationalize that those from more cohesive families may receive greater emotional and social support in times of distress, 
promoting more security within the individual. Thus, results support the notion that family cohesion may act as a protective factor that can mitigate the risk of stress and foster the establishment of psychological security.

Overall, college students with high perceived stress and low family cohesion may be at greatest risk of developing insomnia symptoms and particularly worth monitoring. Even when one's perceived stress is low, college students with low family cohesion may be at greater risk for insomnia problems. The results highlight a crucial need for support systems to be established that may provide the necessary resources absent in incohesive family units. As many societies are seeing an uptick in domestic abuse during the pandemic (e.g., BBC, 2020; Galloway, 2020; Taub \& Bradley, 2020), the pandemic has inadvertently shed light on the institutional system's failure to adequately address the needs of vulnerable populations. Results from this study may further aid in tailoring psychotherapy to address the key areas within patients' lives that may be feeding into negative physiological and psychological outcomes.

\subsection{Limitations}

Several limitations need to be considered when interpreting the implications of the findings. Firstly, the survey nature of data collection limits inference of causality. Future research may examine longitudinal data to confirm the findings of this study and further examine whether the negative sleep outcomes persist long-term. Secondly, all variables were assessed via selfreport measures, which might affect the validity of the present study. Future research may opt to measure physiological readings of sleep quality. Finally, COVID-19 is currently spreading in many countries in the world, so further verification with samples from other countries that may 
be more heavily affected by COVID-19 (e.g., United States of America) may warrant further inquiry. Despite these limitations, however, the current study has several theoretical and practical contributions. From a theoretical perspective, this study further extends previous research by examining the mediating role of sense of security and the moderating role of family cohesion. From a practical perspective, results from this study may be used to examine the efficacy of family-oriented social interventions in mitigating the negative effects of insecurity on sleep problems.

\section{Conclusion}

In summary, while further replication and extension of the current results are still needed to make definitive claims, this study is an important step in unpacking how perceived stress relates to the development of insomnia symptoms among Chinese college students. This study showed that a sense of security serves as one potential mechanism by which perceived stress were associated with more insomnia. The focus on sense of security brings additional nuances in linking perceived stress to insomnia of college students. Moreover, the relationship between perceived stress and sense of security was moderated by family cohesion, and this relationship appear to be weaker for college students with high family cohesion than for those with low family cohesion.

\section{References}

Ayittey, FK., Dzuvor, C., \& Ayittey, M. K. (2020). Updates on Wuhan 2019 novel coronavirus epidemic. J Med Virol, 92(04), 403-407. https://doi.org/10.1002/jmv.25695.

Bannink, R., Broeren, S., Van de Looij Jansen, P. M., \& Raat, H. (2013). Relationship between 
quality of parent-child attachment, adverse life events and mental health. Multidisciplinary sciences. 8(11), 1-7. https://doi.org/10.1371/journal. Pone. 0080812.

BBC. (2020). Coronavirus: Isle of man's domestic abuse rate rises $21 \%$ during pandemic. Retrieved July 28, 2020, https://www.bbc.com/news/world-europe-isle-of-man-53370612.

Brand, S., Beck, J., Kalak, N. et al. (2011). Dream recall and its relationship to sleep, perceived stress, and creativity among adolescents. Journal of Adolescent Health, 49(5), 525-531. https://doi.org/10.1016/j. jadohealth. 2011.04.004.

Bronfenbrenner, U. (2005). Making human beings human: Bioecological perspectives on human development. Thousand Oaks, CA: Sage Publications Ltd.

Buysse, D. J., Reynolds, C. F. 3rd., Monk, T. H., Berman, S. R., Kupfer, D. J. (1989). The pittsburgh sleep quality index: a new instrument for psychiatric practice and research. Psychiatry Research, 28, pp. 193-213. https://doi.org/10.1016/0165-1781 (89) 90047-4.

Buzohre, E, L., Cheng, J., Liang, Y. M. (2018). Posttraumatic stress disorder and depression prevalence among enterprise employees after an accident disaster. China Journal of Public Health, 34(10), 1355-1359. https://doi.org/10.11847/zgggws1117242.

Coe, J. L., Davies, P. T., \& Sturge-Apple, M. L. (2017). The multivariate roles of family instability and interparental conflict in predicting children's representations of insecurity in the family system and early school adjustment problems. Journal of Abnormal Child Psychology, 45(2), 211-224. https://doi.org/10. 1007/s10802-016-0164-6.

Cohen, S., Kamarck, T., \& Mermelstein, R. (1983). A global measure of perceived stress. Journal of Health and Social Behavior, 24(4), pp. 385-396. https://doi.org/10. 
$2307 / 2136404$.

Cong, Z., \& An, L. J. (2004). Developing of security questionnaire and its reliability and validity. Chinese Mental Health Journal, 18(2), 97-99.

Cummings, E. M., Koss, K. J., \& Davies, P. T. (2015). Prospective relations between family conflict and adolescent maladjustment: security in the family system as an explanatory mechanism. Journal of Abnormal Child Psychology, 43, 503-515. https://doi.org/10.1007/s10802-014-9926-1.

Davies, P. T., Winter, M. A., \& Cicchetti, D. (2006). The implications of emotional security theory for understanding and treating childhood psychopathology. Development and Psychopathology, 18, 707-735. https://doi.org/10.1017/S0954579406060354.

Dean, W. N., \& Lawrence, H. C. (1983). Locus of control and control perceptions and the relatio nship between life stress and psychological disorder. American Journal of Community Psychology, 11(6), 705-722. https://doi.org/10. 1007/BF00896604.

Demby, K. P., Riggs, S. A., Kaminski, P. L. (2017). Attachment and family processes in children's psychological adjustment in middle childhood. Journal Citation Reports, 56(1), 234-249. https://doi.org/ 10.1111/famp.12145.

Donarelli, Z., Dennis, M., Kivlighan, Jr., \& Allegra, A. (2016). How do individual attachment patterns of both members of couples affect their perceived infertility stress? An actorpartner interdependence analysis. Personality and Individual Differences, 92, 63-68. https://doi.org/10.1016/j.paid.2015.12.023. 
Dou, F., Wang, M. H., \& Gao, X. (2019). Effect of study pressure on sleep quality of senior three students: a moderated mediating model. Chinese Journal of Clinical Psychology, 27(06), 1275-1278+1282. https://doi.org/10.16128/j.cnki.1005-3611.2019.06.041.

Eskildsen, A., Fentz, H. N., \& Andersen, L. P. (2017). Perceived stress, disturbed sleep, and cognitive impairments in patients with work-related stress complaints: a longitudinal study. Stress, 20(4), 371-378. https://doi.org/10.1080/10253890.2017.1341484.

Fei, L. P., Shen, Q. J., Zheng, Y. P., Zhao, J. P., Jiang, S. A., Wang, L. W. (1991). Preliminary evaluation of chinese version of FACES II and FES: Comparison of normal families and families of schizophrenic. Chinese Mental Health Journal, 5(5), 198-202.

Folkman, S., Lazarus, R. S., \& Dunkel-Schetter, C. (1986). Dynamics of a stressful encounter: cognitive appraisal, coping, and encounter outcomes. Journal of Personality Social Psychology, 50(5), 992-1003. https://doi.org/10.1037//0022-3514.50.5.992.

Galloway, A. (2020-7-13). Domestic violence on the rise during pandemic. The Sydney Morning Herald.

Gerber, M., Hartmann, T., \& Brand, S. (2010). The relationship between shift work, perceived stress, sleep and health in swiss police officers. Journal of Criminal Justice, 38(6), 11671175. https://doi.org/10.1016/j.jcrimjus.2010.09.005.

Gomes, A. R., Faria, S., \& Lopes, H. (2016). Stress and Psychological Health: Testing the mediat ing role of cognitive appraisal. Western Journal of Nursing Research, 38(11), 14481468. https://doi.org/10.1177/0193945916654666.

Hak, C. k., Bongwhakim. (2018). Influences of quality and satisfaction of domiciliary visit care 
services on family support burdens-The mediating effect verification of family cohesion and family adaptability. Korean Journal of Local Government \& Administration Studies, 32(3), 115-137. https://doi.org/10.18398/kjlgas.2018.32.3.115.

Hancock, G. R., \& Mueller, R. O. (2010). The reviewer's guide to quantitative methods in the social sciences. The reviewer's guide to quantitative methods in the social sciences. New York, NY: Routledge.

Harvey, A. G. (2002). A cognitive model of insomnia. Behaviour Research and Therapy, 40(8), 869-893. https://doi.org/10.1016/S0005-7967(01)00061-4.

Hayes, A. F. (2013). Introduction to mediation, moderation, and conditional process analysis: A regression-based approach. New York: Guilford Press. https://doi.org/10.1111/jedm.12050.

Huan, M. X. (2018). Investigation and analysis of college students' learning stress and sleep quality. Medical Information, 31(15), 106-109. https://doi.org/10.3969/j.issn.cu10061959.2018.15.033.

Jin, Y. B., Lan, F., Sun, W. J. (2011). Cognitive models of insomnia: a lecture. Chinese Journal of Mental Health, 25(7), 496-499. https://doi.org/1000-6729 (2011) 007-0496-04.

Jobe-Shields, L., Williams, J., \& Hardt, M. (2017). Predictors of emotional security in survivors of interpersonal violence. Journal of Child and Family Studies, 26(10), 2834-2842. https://doi.org/10.1007/s10826-017-0799-0.

Johnson, E. O., Roth, T., \& Breslau, N. (2006). The association of insomnia with anxiety disorders and depression: Exploration of the direction of risk. Journal of Psychiatric Research, 40, 700-707. https://doi.org/10.1016/j.jpsychires.2006.07.008. 
Kliewer, W., Murrelle, L., Prom, E., Ramirez, M., Obando, P., Sandi, L., \& del Carmen Karenkeris, M. (2006). Violence exposure and drug use in central American youth: Family cohesion and parental monitoring as protective factors. Journal of Research on Adolescence, 16(3), 455-478. https://doi.org/10.1111/j.1532-7795.2006.00502.x.

Kong, Y. (2010). The influence of work pressure on the job security of enterprise employees. $D$, QuFu Normal University.

Lazarus, R. S., \& Folkman, S. (1984). Coping and Adaptation. New York: The Handbook of Behavioral Medicine, 282-325.

Letourneau, N. L., Duffet-Leger, L., Levac, L., Watson, B., \& Young-Morris, C. ( 2011 ). Socioeconomic status and child development: A meta-analysis. Journal of Emotional and Behavioral Disorders, 15(3), 1-14. https://doi.org/10.1177/1063426611421007.

Li, D. (2012). Multiple ecological risk factors and adolescents' social adaptation: how risks should be modeled and what are their mechanisms (Unpublished doctoral dissertation). Guangzhou: South China Normal University. Chicago.

Li, S. W., Zhao Z. X., \& Pan, J. Y. (2006). Consensus on definition, diagnosis and medication therapy of insomnia. Chinese Journal of Neurology, 39, 141-143.

Li, X. Y., Wei, X. Y., Chen, H. D., Gao, L. F., \& Li, W. J. (2019). Relationship between perceived stress and perceived sleep quality: a dual-stage moderated mediation model among university students. Chinese Journal of Clinical Psychology, 27(02), 351-355. https://doi.org/10.16128/j.cnki.1005-3611.2019.02.029.

Lin, X. Y., Li, L. F., Heath, M. A., Chi, P., Xu, S. S., \& Fang, X. Y. (2018). Multiple levels of 
family factors and oppositional defiant disorder symptoms among Chinese children. Family Process, 57(1), 195-210. https://doi.org/10.1111/famp.12269.

Liu, X. H. (2016). The relationship of sleep quality, perceived stress, resilience and social support among community-dwelling adults. D, Shandong University.

Liu, X. H., Liu, C. Q., \& Tian, X. H. (2015). Perceived stress and sleep quality: resilience as a mediator and moderator. Chinese Journal of Public Health, 31(6), 793-796. https://doi.org/10.11847/zgggws2015-31-06-29.

Magnusson, D., \& Stattin, H. (1998). Person context interaction theories. In W. Damon \& R. M. Lerner (Vol. Ed.), Handbook of child psychology: vol. 1. Theoretical models of human development. New York: Wiley. https://doi.org/urn:nbn:se:oru:diva-6533.

Maslow, A. H., Hirsh, E., Stein, M., Honigmann, I. (1945). A clinically derived test for measuring psychological security-insecurity. The Journal of General Psychology, 33(1), 21 - 41. https://doi.org/10.1080/00221309.1945.10544493.

McCann, S. J. H., Stewin, L. L. (1998). Worry, anxiety, and preferred length of sleep. Journal of Genetic Psychology, 149(3), 413-418. https://doi.org/10.1080/00221325.1988.10532169.

Mikulincer, M., \& Shaver, P. R. (2015). An attachment perspective on prosocial attitudes and behavior. In D. A. Schroeder \& W. G. Graziano (Eds.), The Oxford handbook of prosocial behavior (pp. 209-230) New York, NY: Oxford University Press. https://doi.org/10.14966/jssp.31.3-210.

Ministry of Education. (2020). Ministry of Education Press Conference: 8.74 million college graduates nationwide in 2020, the employment situation in the first half of the year is 
complex and severe. Dazhong • Poster News, http://www.dzwww.com/xinwen/guoneixinwen/202002/t20200212_5020436.htm.

Olson, D. H. (1986). Circumplex model VII: validation studies and FACES III. Family Process, (25), 337-351. https://doi.org/10.1111/j.1545-5300.1986.00337.x.

Olson, D. H., Portner, J., \& Bell, R. (1982). FACES II: Family adaptability and cohesion evaluation scales. Unpublished manuscript, Family Social Science, University of Minnesota.

Qin, Y. H., Wan, X., Qu, S. S., \& Chen, G. (2015). Family cohesion and school belonging in preadolescence: Examining the mediating role of security and achievement goals. SHS Web of Conferences (19). EDP sciences. https://doi.org/10.1051/shsconf/20151902004.

Redeker, N. S., Conley, S., Anderson, G., Cline J., Andrews L., Mohsenin V., Jacoby, D., \& Jeon, S. (2020). Effects of cognitive behavioral therapy for insomnia on sleep, symptoms, stress, and autonomic function among patients with heart failure. Behavioral Sleep Medicine, 18(2). https://doi.org/10.1080/15402002.2018.1546709.

Roth, N., Lev-Wiesel, R., Shochat, T. (2019). "How do you sleep?" sleep in self-figure drawings of young adolescents in residential care facilities-An exploratory study. Sleep Medicine, 60. https://doi.org/10.1016/j.sleep.2019.01.028.

Tang, W. J., Wang, G., Hu, T., Dai, Q., Xu, J., Yang, Y. (2018). Mental health and psychological problems among Chinese left-behind children: A cross-sectional comparative study. Journal of Affective Disorders, 241, 133-141. https://doi.org/10.1016/j.jad.2018.08.017.

Taub, A., \& Bradley, J. (2020-7-2). As domestic abuse rises, U.K.failings leave victims in peril. The New York Times. 
Tong, H. J. (2004). Model of SARS stress and it's character. Acta Psychologica Sinica, (1), 103109.

Van Bavel, J. J., Baicker, K \& Boggio, P. S., Capraro, V., Cichocka, A., Cikara, M ... Willer, R. (2020). Using social and behavioural science to support COVID-19 pandemic response. Nature Human Behaviour, (4), 460-471. https://doi.org/10.1038/s41562-020-0884-z.

Vazsonyi, A. T., Jiskrova, G. K., \& Ksinan, A. J. (2018). Sleep, low self-control, and deviance: direct and indirect links across immigrant groups and socioeconomic strata. Journal of Adolescence, 68, 40-49. https://doi.org/10.1016/j.adolescence.2018.06.002.

Williams, P. G., Cribbet, M. R., Rau, H. K., Gunn, H. E., \& Czajkowski, L. A. (2013). The effects of poor sleep on cognitive, affective, and physiological responses to a laboratory stressor. Annals of Behavioral Medicine, 46(1), 40-51. https://doi.org/10.1007/s12160-0139482-x.

World Health Organization. (2020). WHO director-general's opening remarks at the media briefing on COVID-19 an emerging global health threat. Journal Infect Public Health, 13(4), 644-646.

Yan, Y. W., Liu, M. Y., Tang, X. D., \& Lin, R. M. (2010). On the relationship among stress response, coping and sleep quality. Advances In Psychological Science, 18(11), 1734-1746.

Yang, Y. Z., Huang, H. T. (2003). An epidemiological study on stress among urban residents in social transition period. Chinese journal of epidemiology, 24(9), 760-764.

Ye, B. J., Lei, X., Yang, J. F., Byrne, P. J., Jiang, X. C., Liu, M. F., \& Wang, X. Q. (2019). Family cohesion and social adjustment of chinese university students: the mediating 
effects of sense of security and personal relationships. Current psychology (New Brunswic, N. J. ), (1). https://doi.org/10.1007/s12144-018-0118-y.

Zhang, X. F., Gao, F. Q., Geng, J. Y., \& Wang, Y. M. (2018). Social avoidance and distress and mobile phone addiction: A multiple mediating model. Chinese Journal of Clinical Psychology, 26(3), 494-497. https://doi.org/10.16128/j.cnki.1005-3611.2018.03.017.

Zhang, Y., Li, F., Wang, Z. H., Zhong, S. J., \& Shi, Q. (2014). The relationship of master graduate students' perceived stress, state-trait anxiety and perfectionism with sleep quality. Psychological Science, 34(6), 1409-1414. https://doi.org/10.16719/j.cnki.16716981.2014.06.021. 